\title{
MEASUREMENT OF THE ELECTRON TEMPERATURE IN DIELECTRIC BARRIER DISCHARGE BY LINE-RATIO METHOD OF OPTICAL EMISSION SPECTROSCOPY
}

\author{
R. B. Tyata ${ }^{1}$, D. P. Subedi ${ }^{2}$, C. S. Wong ${ }^{3}$ \\ ${ }^{1}$ Department of Electrical Engineering, Khwopa College of Engineering, Libali-2, Bhaktapur, Nepal \\ ${ }^{2}$ Department of Natural Science, Kathmandu University, Dhulikhel, Nepal \\ ${ }^{3}$ Plasma Technology Research Centre, Physics Department, University of Malaya, 50603 KualaLumpur,Malaysia
}

\begin{abstract}
In this paper, experimental results of atmospheric pressure dielectric barrier discharge (DBD) produced in air and nitrogen gas have been presented. The discharge was generated using a high voltage $(0-20 \mathrm{kV})$ power supply operating at $10-30 \mathrm{kHz}$ in hemispherical electrodes system with dielectric barrier of glass between the electrodes. Optical emission spectroscopy was used for the characterization of the discharge produced at atmospheric pressure. The emission spectra in the range of $200 \mathrm{~nm}$ to $450 \mathrm{~nm}$ have been analyzed to estimate the electron temperature by line intensity ratio method. The results show that the electron temperature is about $0.70 \mathrm{eV}$ in air and 0.71 in nitrogen.
\end{abstract}

Keywords: DBD, air, nitrogen, electron temperature

\section{Introduction}

The DBD is an electrical discharge that is generated between two electrodes using AC power supply at which at least one electrode is covered by an electrical insulator. Common materials for dielectric barriers are glass, quartz, ceramics, enamels, plastic films, silicon rubber, sand other materials. Researchers mostly used the planar reactor with both electrodes covered with a dielectric. These electrodes are mostly disc-shaped and have a diameter of about $4 \mathrm{~cm}$. Cylindrical reactors, which build gas flow controller and facilitates small variation of inside pressure (Golubovskii et al., 2001, Kogelschatz et al., 2003 Mangolini et al., 2004) are used for industrial propose. The experimental investigations of the dielectric barrier were reported initially by Werner von Siemens (Siemens, 1857). The research mainly focused on the generation of ozone.

\footnotetext{
*Corresponding author: R. B. Tyata

Department of Electrical Engineering, Khwopa College of Engineering, Libali-2, Bhaktapur, Nepal

Email: rbtyata@yahoo.com

(Received: 2015 June 02 Accepted: 2015 July 03)
}

In the beginning of the 20th century, Emile Warburg in Berlin conducted important investigations which lead to a much better control of these discharges (Warburg, 1904). In 1920 Becker and Otto separately industrialized the designs of the ozone generators (Becker, 1920, Otto, 1929).

In 1932 it was discovered by Buss that the breakdown of air between planar parallel electrodes covered by dielectrics always occurs in a large number of tiny short lived current filaments (Buss, 1932).

The atmospheric pressure DBD typically operates in the filamentary mode, but under specific operating conditions it is also possible to operate it in a diffuse mode, where spatial homogeneity in the direction parallel to the electrodes is obtained. This enables the discharge to be used for homogeneous surface treatments at atmospheric pressure.

Bartnikas found that helium AC discharges between closely spaced plane parallel electrodes, metallic or covered with a dielectric layer, can exhibit diffuse glow discharge characteristics (Bartnikas, 1968). The successes of this discharge mode were also investigated around 1976 when Donohoe finished 
his $\mathrm{PhD}$ research on the development and characterization of glow discharges in mixtures of helium and acetylene in his setup (Donohoe et al., 1976).

In 1987 and afterwards uniform dielectric barrier glow discharges were developed in the research group of Okazaki. They used an electrode configuration using two metal foils covered with a special metal mesh and ceramic dielectrics. In this way homogeneous discharges were obtained in helium, nitrogen, air, oxygen and argon, even with or without the addition of organic precursors. They proposed to use the term atmospheric pressure glow discharge or APGD (Okazaki et al., 1987). Roth and coworkers also developed at the University of Tennessee a similar uniform dielectric barrier discharge reactor. Without using any special metal mesh on the electrodes they were able to obtain uniform glow discharges in helium and argon between electrodes with a separation of several centimeters (Roth et al., 1995).

In 1998 and afterwards Massines and her team made major contributions to the understanding of the glow mode in the atmospheric pressure DBD using both experiment sand simulations on mainly $\mathrm{He}$ and $\mathrm{N}_{2}$ discharges (Massines et al., 1998, Massines et al.,
2005). They made important steps in understanding about elementary processes which are responsible for the existence of the glow mode. More recent activities of several teams (Laroussi et al., 2004, Deng et al., 2004, Chirokov et al., 2005, Iqbal et al., 2009, Martens et al., 2010) focused on obtaining high temporally and spatially resolved spectroscopic measurements as well as on developing detailed theoretical models, where the objective mainly lies in obtaining a better understanding in order to control these sometimes unstable transient discharges.

Another crucial mechanism in a DBD is the charge accumulation on the dielectric material. Some materials accumulate charges much more homogeneously than others. In the group of Van de Sanden an electronic feedback system was developed, which is based on limiting the current in order to prevent transitions to an arc discharge, a much more powerful discharge which would damage the dielectric materials (Aldea et al., 2005).

The electron temperature is the most fundamental parameter in gas discharges and play a very important role in understanding the discharge physics and optimization of the operation of plasma (Napartovich et al., 2001).
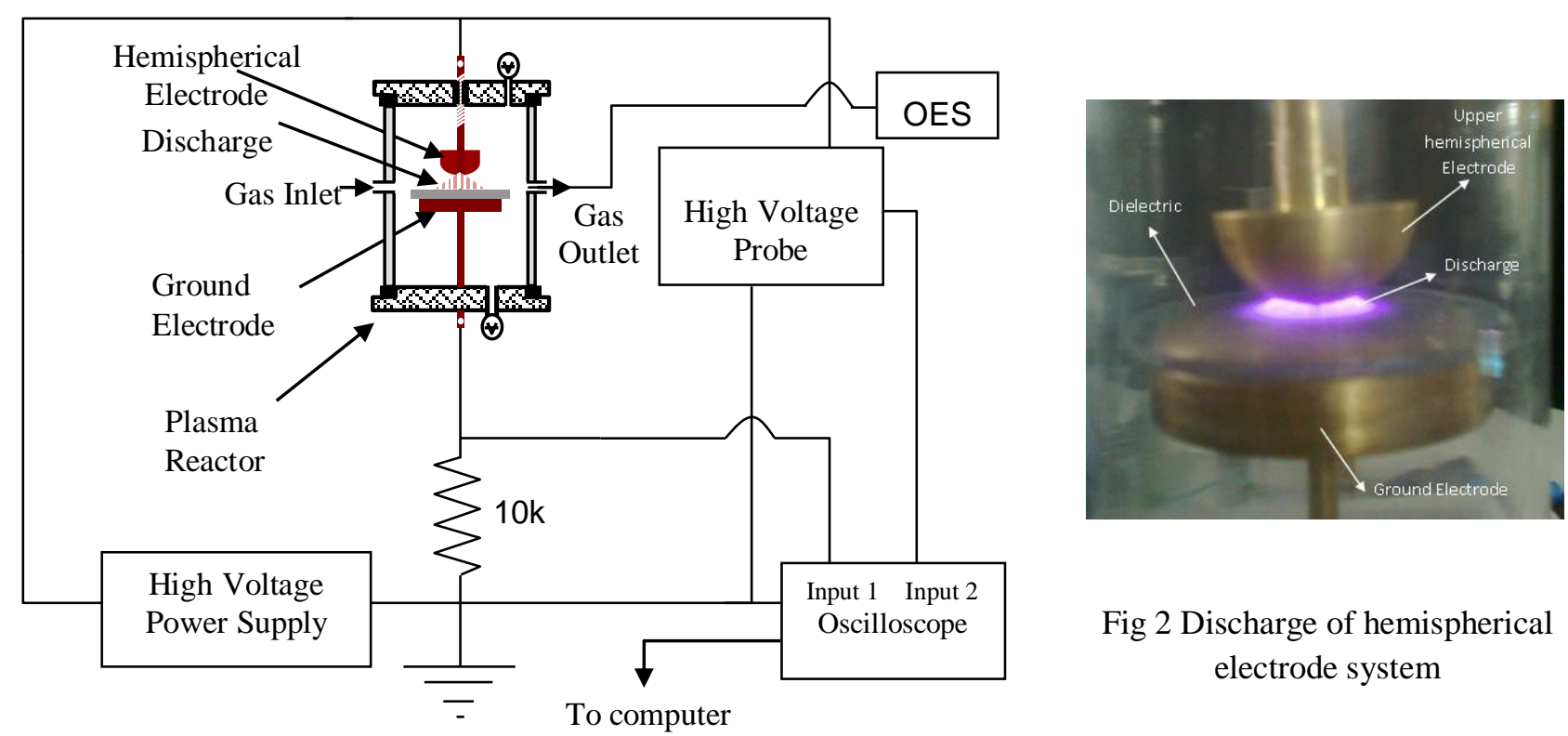

Fig 2 Discharge of hemispherical electrode system

Fig 1 Schematic diagram of experimental setup 
In this work, the electron temperature of the DBD has been determined by means of optical emission spectroscopy using line intensity ratio method. OES is a technique which analyzes the light emitted from the DBD. The light originates from the excited states decaying to lower energy levels in atoms and molecules due to many kinds of processes. OES can be used to identify the types of excited species present in the plasma. It can also be used to estimate the temperature of such species which is obtained from the analysis of the energy distributions of particles and their respective populations. The transitions between electronic energy levels correspond to wavelength of light from ultra-violet to visible range.

\section{Experimental Setup}

The schematic diagram of experimental arrangement of this system is shown in Fig 1. The upper electrode is hemispherical in shape with $3.15 \mathrm{~cm}$ diameter and $1.5 \mathrm{~cm}$ height and the lower electrode is circular with $5.05 \mathrm{~cm}$ diameter and $1.02 \mathrm{~cm}$ thickness. Both electrodes are made of brass. Polycarbonate plate of thickness $1 \mathrm{~mm}$ was used as a dielectric barrier. A high voltage AC power supply was used and the applied rms voltage was in the range of $3-7 \mathrm{kV}$ at a frequency of $28 \mathrm{kHz}$. The gap was varied in the range of 1-2 $\mathrm{mm}$ and the gas flow rate was set at 1-2 lit/min. Electrical characterization was carried out with the help of a high voltage probe coupled to Tektronix TDS2002 digital oscilloscope. The discharge obtained in the hemispherical electrode system is shown in Fig 2.

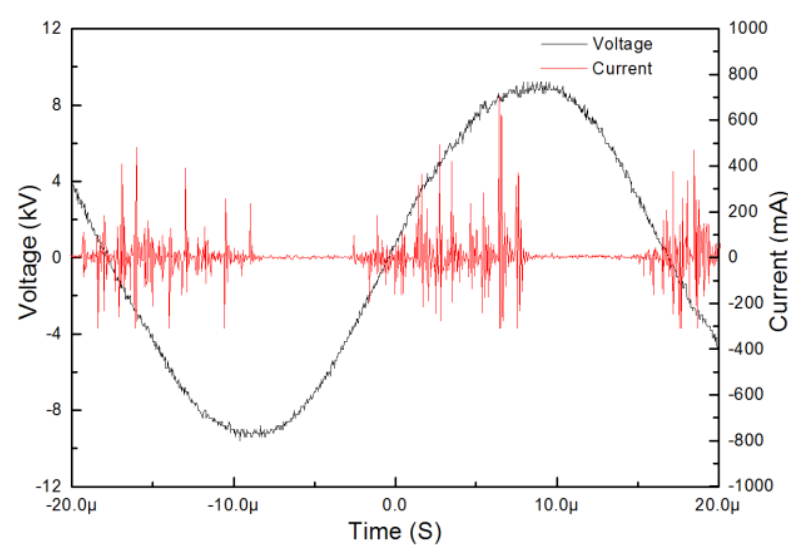

Fig 3 (a)

\section{Result and Discussion}

\subsection{Electrical Characterization}

Figs 3(a-b) show the voltage and current wave forms of the DBD in air and nitrogen in $2 \mathrm{~mm}$ gap respectively at a frequency of $28 \mathrm{kHz}$. Figs (c-d) correspond to the photographs of air and nitrogen discharges with $2 \mathrm{~mm}$ gap between the electrodes. The comparison of the current wave forms of the discharges in air and nitrogen indicates that the density of current pulses (bursts) per half cycle and the amplitude of the discharge current is smaller in the case of nitrogen flow. It is evident that the number of current pulses per half cycle increase with the increase in applied voltage for both values of the electrode spacing (Tyata et al., 2012).

\subsection{Measurement of Electron Temperature}

Figs. 4(a) and 4(b) show the OES from the discharge of air and nitrogen between $250 \mathrm{~nm}$ and $450 \mathrm{~nm}$ with $2 \mathrm{~mm}$ electrode gap in hemispherical electrode system. The spectrum is analyzed for determination of electron temperature.

Four suitable lines (two for NI and NII) are chosen and electron temperature is estimated using the line intensity ratio method. For the measurement of electron temperature, equation (1) is used (Beaker, 1920, Roth et al., 1995).

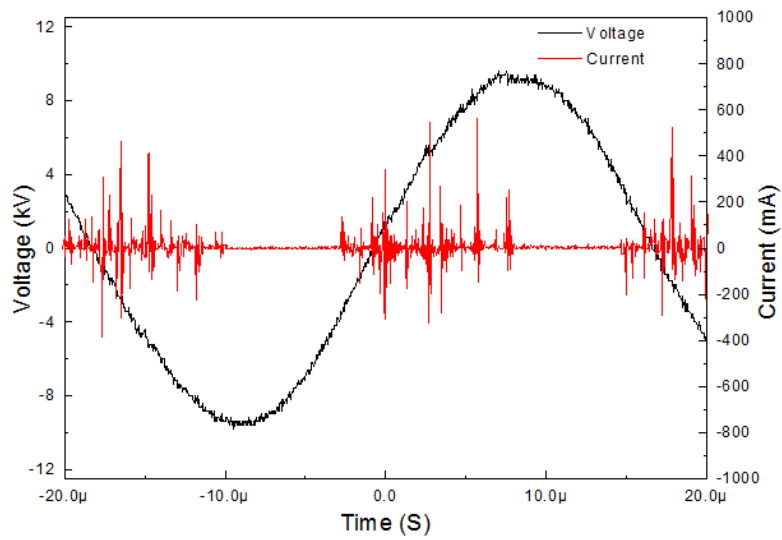

Fig 3 (b) 


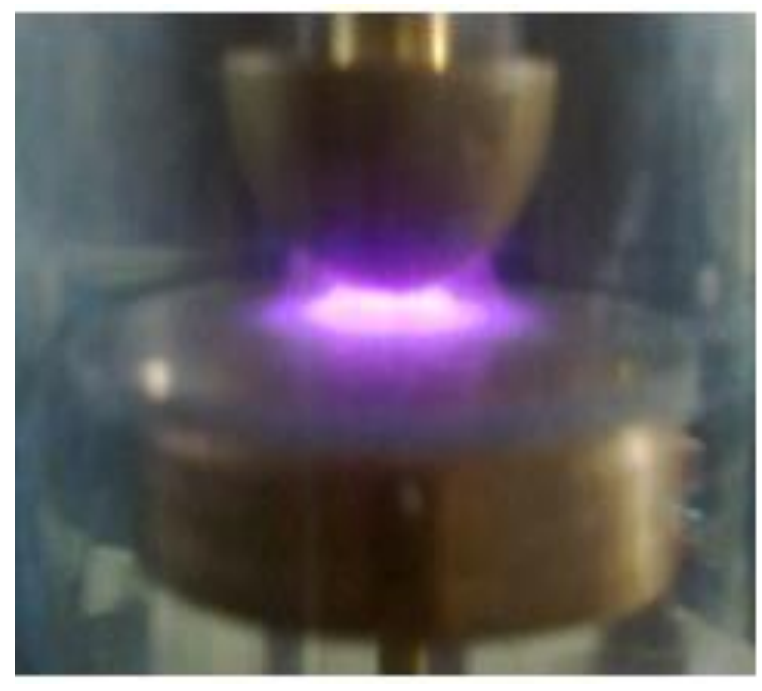

Fig 3 (c)

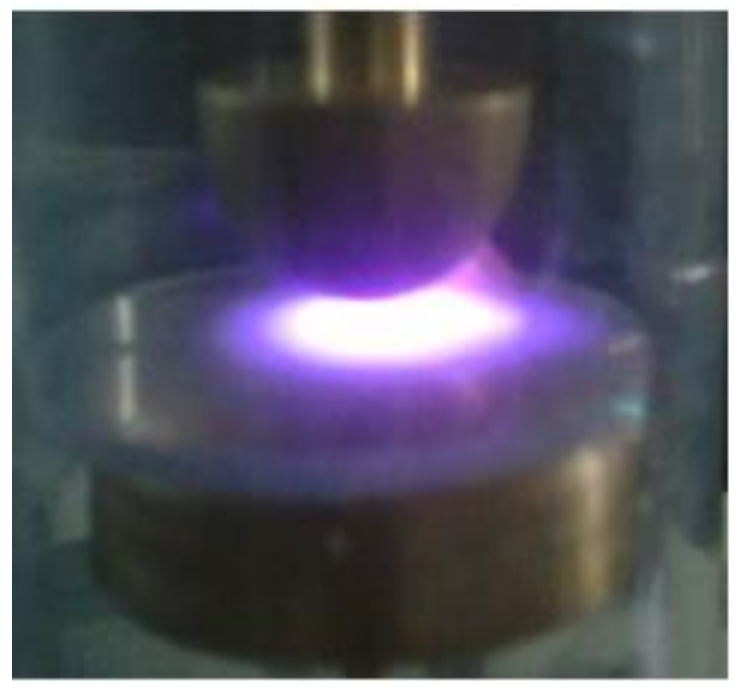

Fig 3 (d)

Fig 3 Voltage and current wave form of DBD in nitrogen with $2 \mathrm{~mm}$ gap using different applied voltage 3$7 \mathrm{kV} \mathrm{rms}$ at $28 \mathrm{kHz}$. The corresponding photographs of the discharge are shown in the adjacent sides.

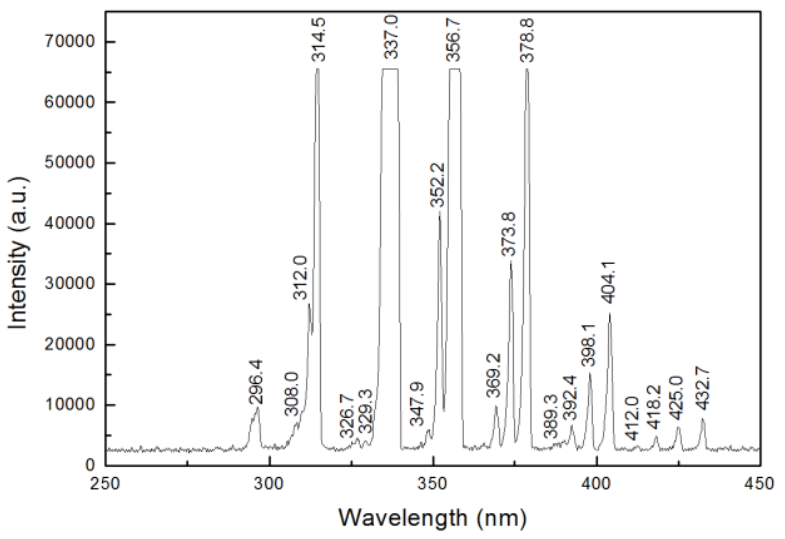

(a)

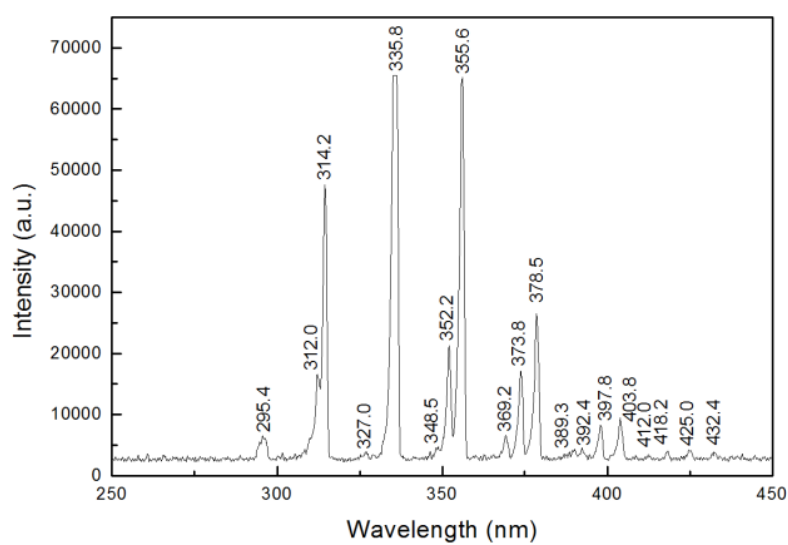

(b)

Fig 4 Optical emission spectrum (250 nm and $450 \mathrm{~nm}$ ) of DBD in air and nitrogen generated at atmospheric pressure using high frequency power supply

$$
\frac{R_{1}}{R_{2}}=\frac{I_{1} / I_{2}}{I_{3} / I_{4}}=\left(\frac{A_{p q}}{A_{x y}}\right)\left(\frac{g_{p}}{g_{x}}\right)\left(\frac{\lambda_{x y}}{\lambda_{p q}}\right)\left(\frac{A_{u v}}{A_{r s}}\right)\left(\frac{g_{u}}{g_{r}}\right)\left(\frac{\lambda_{r s}}{\lambda_{u v}}\right) \exp \left[-\frac{E_{p}-E_{x}-E_{r}+E_{u}}{k T_{e}}\right] \ldots
$$




\begin{tabular}{|l|l|l|l|}
\hline $\mathrm{NI}=(389 . \mathrm{nm})$ & $\mathrm{A}_{\mathrm{pq}}=2.50 \times 106 \mathrm{~s}^{-1}$ & $\mathrm{~g}_{\mathrm{p}}=4$ & $\mathrm{E}_{\mathrm{p}}=10.680 \mathrm{eV}$ \\
\hline $\mathrm{NI}=(425.0 \mathrm{~nm})$ & $\mathrm{A}_{\mathrm{rs}}=2.24 \times 105 \mathrm{~s}^{-1}$ & $\mathrm{~g}_{\mathrm{r}}=4$ & $\mathrm{E}_{\mathrm{r}}=12.000 \mathrm{eV}$ \\
\hline $\mathrm{NII}=(392.4 \mathrm{~nm})$ & $\mathrm{A}_{\mathrm{xy}}=7.99 \times 106 \mathrm{~s}^{-1}$ & $\mathrm{~g}_{\mathrm{x}}=5$ & $\mathrm{E}_{\mathrm{x}}=20.603 \mathrm{eV}$ \\
\hline $\mathrm{NII}=(412.0 \mathrm{~nm})$ & $\mathrm{A}_{\mathrm{uv}}=4.37 \times 104 \mathrm{~s}^{-1}$ & $\mathrm{~g}_{\mathrm{u}}=3$ & $\mathrm{E}_{\mathrm{u}}=20.400 \mathrm{eV}$ \\
\hline
\end{tabular}

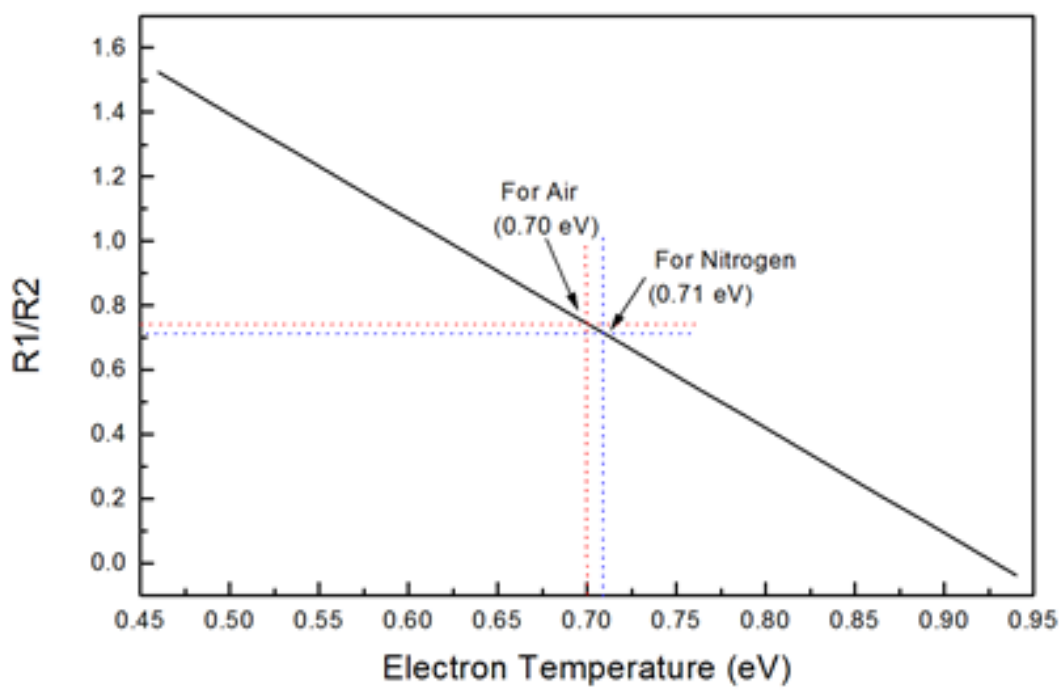

Fig 5 Relation between $R_{1} / R_{2}$ and electron temperature $(\mathrm{Te})$

Table 1: The value of intensity of four spectral lines in air and nitrogen discharge

\begin{tabular}{|c|l|c|c|c|c|c|c|}
\hline S.N. & Gas & $\mathrm{I}_{1}$ & $\mathrm{I}_{2}$ & $\mathrm{I}_{3}$ & $\mathrm{I}_{4}$ & $\mathrm{I}_{1} / \mathrm{I}_{2}$ & $\mathrm{I}_{3} / \mathrm{I}_{4}$ \\
\hline 1 & Air & 2873 & 3895 & 6293 & 6374 & 0.737 & 0.987 \\
\hline 2 & Nitrogen & 3965 & 4382 & 3944 & 3155 & 0.904 & 1.250 \\
\hline
\end{tabular}

The value of $\lambda$ and $I$ are obtained from the observation, and the values of $\mathrm{A}_{\mathrm{ij}}, \mathrm{g}_{\mathrm{i}}$, and $\mathrm{E}_{\mathrm{i}}$ are obtained from NIST atomic Spectra Database.

Consider two NI lines with wavelengths $389.3 \mathrm{~nm}$ and $425.0 \mathrm{~nm}$ and two NII lines with wavelengths $392.4 \mathrm{~nm}$ and $412.0 \mathrm{~nm}$.

Using the above data we obtain

$$
\frac{R_{1}}{R_{2}}=3.6 \times 10^{-2} \exp \left[\frac{1.923}{k T_{e}}\right]
$$

In the Table $1, I_{1}, I_{2}, I_{3}$ and $I_{4}$ are the value of intensity of spectral lines of wavelengths 389.3 $\mathrm{nm}, \quad 392.4 \mathrm{~nm}, \quad 425.0 \mathrm{~nm}$, and $412.0 \mathrm{~nm}$ respectively. Fig. 4 shows the plot between $R_{1} / R_{2}$ and $T_{e}$ with different values of $T_{e}$. This graph is used to determine the electron temperature using the value of $R_{1} / R_{2}$ obtained from the observation. From the observation, $\mathrm{R}_{1} / \mathrm{R}_{2}=0.74$ for air and 0.72 for nitrogen which corresponds to electron temperature of $0.70 \mathrm{eV}$ for air and $0.71 \mathrm{eV}$ for nitrogen. From the observed values of $R_{1} / R_{2}$, it can be concluded that the electron temperature lies between $0.5 \mathrm{eV}$ and $1.5 \mathrm{eV}$. Result of optical characterization of DBD produced in atmospheric pressure air are also explained in our earlier work ( Shrestha et al., 2012 Tyata et al., 2013).

\section{Conclusion:}

The spectral lines analysis is a good non perturbing method for determining the electron temperature in air and nitrogen at atmospheric pressure dielectric barrier discharge. The 
electron temperature is determined by line intensity ratio method and is about $0.70 \mathrm{eV}$ in air and $0.71 \mathrm{eV}$ in nitrogen.

\section{Acknowledgement}

The Research was supported by the University Grants Commission (UGC), Nepal.

\section{References:}

[1] Aldea E., Peeters P., de Vries H., and van de Sanden M. C. M., 2005. Surf. Coat. Technol., 200:46-50

[2] Balcon N., Aanesland A. and Boswell R, 2007. Plasma Source Science. Technol. 16: 217-225

[3] Bartnikas R., 1968. Brit. J. Appl. Phys., 2(1):659-61

[4] Becker H., Wiss. Veroff. Siemens-Konzern, 1:76, 1920.

[5] Buss K., 1932. Arch. Elektrotech., 26:261

[6] Chirokov A. V., 2005.. Ph.D. thesis,Philadelphia, PA, USA, Drexel University

[7] Deng X. T., and Kong. M. G., 2004..IEEE Trans. Plasma Sci., 32(4):1709-15

[8] Donohoe K. G., 1976. Ph.D. thesis, California Institute of Technology,

[9] Golubovskii Y. B., Maiorov V. A., Behnke J., F, Tepper J. and Lindmayer. M., 2001. J. Phys. D: Appl. Phys., 37:1346-56

[10] Iqbal. M. M., 2009. Ph.D. thesis, School of Physical Sciences, Dubin City University

[11] Kogelschatz. U., 2003. Plasma Chemistry and Plasma Processing, 23:1-46
[12] Laroussi M., Lu X., Kolobov V., and Arslanbekov. R., 2004. J. Appl. Phys., 96(5):3028-30

[13] Mangolini L., Anderson C., Heberlein J. and Kortshagen U., 2004. J. Phys. D: Appl. Phys., 37(7):1021-30

[14] Martens. T., 2010, .Ph.D. thesis, Antwerpen University

[15] Massines F., dGherardi N., Naude N. and Segur. P., 2005.Plasma Sources Sci. and Technol., 47 (12B): B557-88

[16] NapartovichA. P., 2001, Plasmas and Polymers, 6:114

[17] Okazaki S., Kogoma M., Uehara M. and Kimura.Y., 1993. J. Phys. D: Appl. Phys., 26:889-92,

[18] Otto M. P., 1929. Bull. Soc. Franc. Elect, 9(90):66

[19] Roth J. R., Tsai P. P., Liu C., Laroussi M. and Spence P. D., 1995. United States Patent US5414324,

[20] Shrestha R., Tyata R. B., Subedi D. P., 2012. Kathmandu university journal of science, engineering and technology 8(I):37-42

[21] Siemens W., 1857. Ann. Phys., 102:66-122

[22] Tyata R. B., Subedi D. P. and Wong C. S., 2010. Kathmandu University Journal of Science, Engineering and Technology, 6(II):6-12

[23] Tyata R. B., Subedi D. P., Shrestha R. S. and Wong C. S., 2013 PRAMANA Journal of Physics, 80(3):507-17

[24] Warburg E., 1904. Ann. Phys., 13(4):464-76 